González-Silva, J.; Fernández-Echeverría, C.; Conejero, M.; Moreno, M.P. (2021). Predictors of Reception Efficacy in Men's U-21 and Absolute World Volleyball. Revista Internacional de Medicina y Ciencias de la Actividad Física y el Deporte vol. 21 (84) pp. 451-466. Http://cdeporte.rediris.es/revista/revista83/artanalisis1268.htm

DOI: https://doi.org/10.15366/rimcafd2021.83.003

\title{
ORIGINAL
}

\section{PREDICTORES DE LA EFICACIA DE RECEPCIÓN EN VOLEIBOL MUNDIAL MASCULINO U-21 Y ABSOLUTO}

\section{PREDICTORS OF RECEPTION EFFICACY IN MEN'S U- 21 AND ABSOLUTE WORLD VOLLEYBALL}

\author{
González-Silva, J.'; Fernández-Echeverría, C. ${ }^{2}$; Conejero, M. ${ }^{3}$ y Moreno, \\ M.P. 4 \\ 1 Profesora Sustituta Interina de la Facultad de Ciencias del Deporte de Cáceres (España) \\ jarags@unex.es \\ 2 Profesora Sustituta Interina de la Facultad de Educación de Sevilla (España) \\ cfecheverria@us.es \\ 3 PDI de la de la Universidad de Extremadura. Fundación Fernando Valhondo Calaff. Facultad \\ de Ciencias del Deporte de Cáceres (España) mconejeros@unex.es \\ ${ }^{4}$ Profesora Titular de Universidad de la Facultad de Ciencias del Deporte de Granada (España) \\ perlamoreno@ugr.es
}

Agradecimientos: Este estudio se ha realizado gracias a la aportación de la Consejería de Economía e Infraestructuras de la Junta de Extremadura a través del Fondo Europeo de Desarrollo Regional. Una manera de hacer Europa. (GR18129).

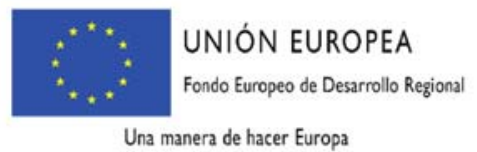

\section{JUNTA DE EXTREMADURA \\ Consejeria de Economia e Infraestructuras}

Código UNESCO/ UNESCO Code: 5899 Otras Especialidades Pedagógicas (Educación Física y Deporte)

Clasificación Consejo de Europa/Classification Council of Europe: 4. Educación Física y deporte comparado/ Physical Education and sport compared.

Recibido 8 de julio de 2019 Received July 8, 2019

Aceptado 14 de noviembre de 2019 Accepted November 14, 2019

\section{RESUMEN}

El objetivo de la investigación fue conocer las variables de recepción que predecían su eficacia, en diferentes niveles de juego (U-21, absoluto) en voleibol masculino. La muestra del estudio estuvo compuesta 3442 acciones de recepción, de las cuales 1894 corresponden a categoría U-21 (U-21 Men's World 
Championship) y 1548 a categoría absoluta (Absolute Men's World Championship). Las variables del estudio fueron: función del receptor, desplazamiento previo del receptor, tipo de recepción, posición del receptor, técnica de recepción, zona de recepción, eficacia de recepción. El análisis de regresión logística multinomial mostró que, el desplazamiento previo del receptor y la técnica de recepción fueron predictoras en ambas categorías, U-21 y absoluta; el tipo de recepción y zona de recepción fueron predictoras únicamente en U-21; la posición del receptor fue predictora únicamente en absoluta. Dicha información puede ayudar al proceso de entrenamiento favoreciendo el diseño de tareas concretas para cada nivel de juego.

PALABRAS CLAVE: rendimiento, análisis del juego, voleibol, recepción.

\section{ABSTRACT}

The aim of the study was to understand which variables of the reception action predict reception efficacy in two different competition categories (U-21, absolute) in male volleyball. The study sample comprised 3,442 serve-reception actions: 1,894 performed by players in U-21 category (U-21 Men's World Championship) and 1,548 performed by players in senior category (senior Men's World Championship). The variables considered as predictors were: receiver player, previous displacement of the receiver, type of reception, receiver position, reception technique reception zone. Logistic regression analysis showed that previous displacement of the receiver and reception technique were predictors of reception efficacy in both categories, U-21 and senior. Type of reception and reception zone were predictors of efficacy in the $\mathrm{U}-21$ category, but not the senior category. Receiver position was predictive of efficacy uniquely for the senior. These may benefit the training process by favouring the design of specific tasks for each level of play.

KEY WORDS: performance, game analysis, reception.

\section{INTRODUCCIÓN}

El análisis del rendimiento es fundamental para los equipos de alto nivel, ya que, además de ayudar a la comprensión del juego (O`Donoghue, 2010), permite, a través de la obtención de los indicadores de rendimiento, conocer los factores que pueden llegar a afectar al juego (Peña, Rodríguez-Guerra, Buscà, \& Serra, 2013). En la actualidad, este análisis del rendimiento se realiza a través del match analysis teniendo, el mismo, un papel fundamental en la mejora del rendimiento en los diferentes deportes (O'Donoghue \& Holmes, 2015). El match analysis es realizado mediante el análisis notacional (Wright, Atkins, \& Jones, 2012), el cual, permite al entrenador conocer aspectos negativos y positivos del rendimiento, pudiendo contribuir al óptimo establecimiento de objetivos (Hughes et al., 2012). El análisis notacional se ha aplicado a deportistas de distintos niveles y en diferentes deportes. Concretamente, en deportes como el voleibol, existen numerosas investigaciones sobre match analysis, centradas fundamentalmente en las acciones de juego finalistas. Por la naturaleza y 
dinámica del juego en voleibol, las acciones no finalistas (mediante las que no se consigue el punto), influyen en las finalistas, siendo importante tener en cuenta la interacción entre ellas (Hale, 2001). Por ello, sería necesario realizar investigaciones centradas en las acciones no finalistas de colocación, recepción o defensa (Fernández-Echeverria, Mesquita, González-Silva, Claver, \& Moreno, 2017).

En voleibol, la recepción, tiene una relación de segundo orden con el ataque (Eom \& Schutz, 1992), por depender éste, en gran medida, de la misma (Parsiaouras, Moustakidis, Charitonidis, \& Kokaridas, 2010). Por ello, la recepción es considerada como una acción importante para el éxito del equipo (Paulo, Zaal, Fonseca, \& Araújo, 2016; Peña et al., 2013). La recepción está relacionada con características antropométricas, psicológicas, aspectos técnicotácticos, coordinación entre jugadores (Sellinger \& Ackermann-Blount, 1985; Stamm, Stamm, \& Thomson, 2005), y con la ejecución del saque del rival (Afonso, Esteves, Araújo, Thomas, \& Mesquita, 2012), pudiendo llegar a condicionar, los factores madurativos, la eficacia de la misma, en diferentes grupos de edad (García-Alcaraz, Palao, \& Ortega, 2014). Además de ello, dicha acción, puede llegar a diferenciar el nivel de los equipos, al ser una acción fundamental para que los equipos estén entre los mejores (Marelić, Resetar, \& Jankovic, 2004).

A pesar de que se conoce la importancia de la recepción en la construcción del juego (Costa et al., 2018), pocos son los estudios centrados en la misma. De ellos, algunos se centran en la figura del libero, Rentero, João, y Moreno (2015) en alto nivel, y Sánchez, González-Silva, Fernández-Echeverría, Claver, y Moreno (2019) en etapas de formación, analizaron la participación y la influencia del libero tanto en la fase de ataque (recepción) como en la fase de defensa (defensa). Otros, han tratado de analizar la recepción en función del saque del equipo contrario, como el estudio de Paulo et al. (2016), en el que pretendieron conocer los aspectos del saque y de la recepción que determinaban la elección del tipo de recepción y su eficacia, concretamente, para ello crearon una tarea en la que ocho jugadores de alto nivel tenían que recibir saques flotantes en dos zonas diferentes del campo, zona uno y zona cinco; o analizar el efecto de la recepción sobre el ataque, como la investigación realizada por Costa et al. (2018), en el que analizaron el efecto de la recepción en el complejo KI, teniendo en cuenta el nivel de oposición de los equipos. Estas investigaciones fundamentalmente se han llevado a cabo en voleibol de alto nivel. Sin embargo, son pocos los estudios desarrollados en los que se ha tratado de conocer cómo las características de la recepción afectan a su eficacia.

Por ello, el objetivo de la presente investigación es analizar las variables de recepción que predicen su propia eficacia, en diferentes niveles de juego (U-21 y absoluto) en voleibol masculino. 


\section{MÉTODO}

\section{Muestra}

La muestra del estudio estuvo compuesta por un total de 3442 acciones de recepción, de las cuales 1894 corresponden a categoría U-21 (U-21 Men's World Championship) y 1548 a categoría absoluta (Absolute Men's World Championship). Dichas acciones corresponden a la observación de un total de 37 partidos, de los cuales 14 son de categoría U-21 y 23 de categoría absoluta.

En la categoría U-21, se observaron 5 partidos de cada una de las cuatro mejores selecciones clasificadas en el Men's Under-21 World Championship. Esto supuso la observación de 53 sets en dicha categoría. En la categoría absoluta, se observaron cuatro partidos de las 12 mejores selecciones participantes de la tercera fase del Men's absolute World Championship, lo que supuso la observación de 87 sets en la categoría absoluta.

\section{Variables}

Las variables del estudio fueron las siguientes:

Función del receptor, definido como el rol del jugador al cual es dirigido el saque para su recepción (Gil-Arias, Claver, Fernández-Echeverría, Moreno, \& Moreno, 2016). Las categorías fueron: receptor delantero, definido como el jugador cuatrero con funciones ofensivas, situado en la zona delantera del campo (dos, tres, cuatro), que recibe el saque; libero, definido como el jugador especializado en defensa y recepción que recibe el saque; y otro, definido como el jugador con funciones diferentes a las del atacante delantero y libero.

Desplazamiento previo del receptor, definido como los desplazamientos que realiza el jugador receptor en el momento que va desde que el sacador realiza el contacto del saque, hasta que el receptor realiza la recepción (Paulo et al., 2016). A los diferentes tipos de desplazamientos definidos por Paulo et al. (2016), longitudinales (anteroposterior), definido como el desplazamiento hacia delante o hacia atrás que realiza el jugador que lleva a cabo la recepción; y laterales (izquierda-derecha), definido como el desplazamiento hacia la izquierda o derecha que realiza el jugador que lleva a cabo la recepción; se añadió la categoría sin desplazamiento, definido como la recepción que realiza el jugador sin que se produzca desplazamiento del mismo (Ureña, Calvo, \& Lozano, 2002).

Tipo de recepción, definido como la posición del receptor en el espacio en el momento de contacto con el balón. Las categorías fueron: dos apoyos, el jugador contacta con el balón con los dos apoyos en el suelo; un apoyo, el jugador contacta con el balón con uno de los dos apoyos en el suelo; de rodillas, el jugador contacta con el balón con una rodilla o dos rodillas en el suelo; sin apoyos, el jugador contacta con el balón con ningún apoyo en el suelo, teniendo ambos pies en el aire (adaptado de Carrero, Fernández-Echeverría, GonzálezSilva, Conejero, \& Moreno, 2017). 
Posición del receptor, definido como la altura de los brazos del receptor en el momento de contacto con el balón (Miller, 2005, 55). Las categorías fueron: alta (por encima de la cadera), el jugador contacta con el balón con los brazos por encima de la cadera; media, (entre la cadera y las rodillas), el jugador contacta con el balón con los brazos entre la cadera y las rodillas; baja (por debajo de las rodillas), el jugador contacta con el balón con los brazos por debajo de las rodillas.

Técnica de recepción, definido como el gesto técnico que realiza el jugador al recibir el balón del saque del equipo contrario. A los diferentes tipos de recepción definidos por Barsingerhorn, Zaal, De Poel, y Pepping (2013) y Benerink, Bootsma, y Zaal (2015), recepción de dedos, definida como la recepción que es realizada por el jugador receptor mediante un toque de dedos; recepción de antebrazos de frente, definida como la recepción que es realizada por el jugador receptor mediante un toque de antebrazos realizado en la frontal; se añadieron las siguientes categorías, antebrazos lateral izquierdo, definida como la recepción que es realizada por el jugador receptor mediante un toque de antebrazos sacando los brazos hacia el lateral izquierdo y antebrazos lateral derecho, definida como la recepción que es realizada por el jugador receptor mediante un toque de antebrazos sacando los brazos hacia el lateral derecho.

Zona de recepción, definido como la zona del campo donde el receptor realiza la recepción del saque. zona uno, definido como la recepción que se realiza en el pasillo de tres metros de ancho por nueve de largo ubicado en la parte derecha del campo; zona seis, definido como la recepción que se realiza en el pasillo de tres metros de ancho por nueve de largo ubicado en la parte central del campo; zona cinco, definido como la recepción que se realiza en el pasillo de tres metros de ancho por nueve de largo ubicado en la parte izquierda del campo; zona de interferencia, definido como la recepción que se realiza en una zona intermedia y de conflicto entre dos receptores (Gil-Arias et al., 2016).

Eficacia de recepción, definido como el rendimiento obtenido con la recepción del saque. Para la valoración de la eficacia se empleó una adaptación del sistema de categorías usado por la Federación Internacional de voleibol, utilizando los criterios empleados en el software "Data Volley System Valuation" (Data Volley, 2010), los cuales han ido usados en investigaciones previas (García-Alcaraz et al., 2014; Palao, Santos, \& Urena, 2006). Los criterios fueron: recepción que no permite primeros tiempos (RNP), definida como la recepción que limita las opciones ataque, no pudiéndose realizar ataques a primeros tiempos; recepción que permite primeros tiempos (RPP), definida como la recepción que permite todas las opciones de ataque; recepción error (RE), definida como la recepción en la que el balón al contactar con los brazos del receptor se va fuera sin posibilidad de ser recuperado o el balón toca el suelo sin que éste sea contactado por ningún jugador.

\section{Procedimiento y recogida de datos}

Todos los partidos fueron grabados sin cortes, con la cámara situada en uno de los fondos de la cancha de juego, asegurando así un plano de visión óptimo. Una 
vez realizada la recogida de datos, los datos se registraron con el software de análisis observacional aplicada al voleibol VA-Sports 1.0.75.

Para garantizar la fiabilidad de la observación, un observador con las siguientes características, Licenciado en Ciencias de la Actividad Física y el Deporte, entrenador Nacional de Nivel III de voleibol, y con cinco años de experiencia como entrenador, realizó un proceso de entrenamiento. Se alcanzaron, en la observación de todas las variables, unos valores de Kappa de Cohen intraobservador superiores a .81, valor mínimo a partir del cual se considera una concordancia casi perfecta (Fleiss, Levin, \& Paik, 2003). Específicamente, los valores obtenidos en cada variable fueron los siguientes: función del receptor (.95), desplazamiento previo del receptor (.81), tipo de recepción (85), posición del receptor (.86), técnica de recepción (.91), zona de recepción (.92) y eficacia de recepción (.81). Para garantizar la fiabilidad temporal de la medida, se desarrolló la misma observación en dos ocasiones, con una diferencia temporal de diez días, obteniendo unos valores de Kappa de Cohen superiores a .81

\section{Análisis estadístico}

En un primer momento se realizó un análisis descriptivo de las diferentes variables con el objetivo de conocer las frecuencias de cada una de las variables de estudio. Posterior a ello, se realizó un análisis inferencial para comprobar las asociaciones entre cada una de las variables estudiadas. Este análisis se presenta a través de las tablas de contingencia, incluyendo los valores de ChiCuadrado y V de Cramer, con corrección de Monte Carlo. El nivel de significación estadística que se consideró fue de $p<.05$. Finalmente, se realizó el análisis predictivo a través del modelo de regresión logística multinomial para conocer el rango predictor de las diferentes variables de las acciones de juego. El nivel de significación estadística que se consideró fue de $p<.05$.

Previo al análisis de regresión, para evitar la inclusión de variables intercorrelacionadas, realizamos una prueba de multicolinealidad. Se consideró el valor de la tolerancia 0.10 y del VIF $<10$ (Hair, Black, Babin, \& Anderson, 2014). Tras esta prueba, ninguna variable se excluyó del modelo al no haber multicolinealidad entre variables. Todos los análisis estadísticos fueron realizados con el software SPSS 23.0 (versión 23.0 para Windows, SPSS, Inc., Chicago, IL, EUA).

\section{RESULTADOS}

Respecto al análisis descriptivo (Tabla 1), en categoría U-21, el jugador "otro" fue el que más realizó la recepción (35.1\%), siendo más frecuente la recepción sin desplazamiento (45.5\%), a través de un tipo de recepción de dos apoyos $(62.4 \%)$, con una posición arriba $(56.5 \%)$, a través de una técnica de recepción de antebrazos de frente $(53.2 \%)$ y en la zona de recepción zona seis $(35.9 \%)$ y con una eficacia que permite primeros tiempos (64.5\%).

En la categoría absoluta, el jugador que más frecuentemente recibió fue el jugador "otro" (38\%), siendo más habitual la recepción sin desplazamiento 
$(47 \%)$, con dos apoyos $(56.6 \%)$, en posición baja (16.1\%), con técnica de recepción de antebrazos de frente $(58.3 \%)$, en la zona seis $(44 \%)$, y con una eficacia que permite primeros tiempos (68.5\%).

Tabla 1. Análisis descriptivo de las variables del estudio.

\begin{tabular}{cccccc}
\hline \multirow{2}{*}{ Variables } & & \multicolumn{2}{c}{$\mathbf{U - 2 1}$} & \multicolumn{2}{c}{ Absoluto } \\
\cline { 3 - 5 } Función del receptor & Categoría & $\mathbf{n}$ & $\mathbf{\%}$ & $\mathbf{N}$ & $\mathbf{\%}$ \\
& Receptor delantero & 652 & 34.4 & 464 & 30 \\
& Otro & $\mathbf{6 6 4}$ & $\mathbf{3 5 . 1}$ & $\mathbf{5 8 9}$ & $\mathbf{3 8}$ \\
& Libero & 578 & 30.5 & 495 & 32 \\
\hline Desplazamiento previo del & Longitudinal & 612 & 32.3 & 454 & 29.3 \\
receptor & Lateral & 421 & 22.2 & 367 & 23.7 \\
& Sin desplazamiento & $\mathbf{8 6 1}$ & $\mathbf{4 5 . 5}$ & $\mathbf{7 2 7}$ & $\mathbf{4 7}$ \\
\hline Tipo de recepción & Un apoyo & 210 & 11.1 & 163 & 10.5 \\
& De rodillas & 198 & 10.5 & 235 & 15.2 \\
Posición del receptor & Sin apoyo & 304 & 16.1 & 274 & 17.7 \\
& Dos apoyos & $\mathbf{1 1 8 2}$ & $\mathbf{6 2 . 4}$ & $\mathbf{8 7 6}$ & $\mathbf{5 6 . 6}$ \\
\hline Técnica de recepción & Alto & $\mathbf{1 0 7 1}$ & $\mathbf{5 6 . 5}$ & 182 & 11.8 \\
& Bajo & 90 & 4.8 & $\mathbf{2 5 9}$ & $\mathbf{1 6 . 1}$ \\
& Medio & 733 & 38.7 & 214 & 13.8 \\
\hline Zona de recepción & Dedos & 555 & 29.3 & 182 & 11.8 \\
& Antebrazos lat. izquierdo & 167 & 8.8 & 250 & 16.1 \\
& Antebrazos lat. derecho & 164 & 8.7 & 214 & 13.8 \\
& Antebrazos de frente & $\mathbf{1 0 0 8}$ & $\mathbf{5 3 . 2}$ & $\mathbf{9 0 2}$ & $\mathbf{5 8 . 3}$ \\
\hline & Zona uno & 543 & 28,7 & 324 & 20,9 \\
& Zona de interferencia & 151 & 8 & 107 & 6,9 \\
& Zona cinco & 520 & 27,5 & 436 & 28,2 \\
\hline Eficacia de recepción & Zona seis & $\mathbf{6 8 0}$ & $\mathbf{3 5 , 9}$ & $\mathbf{6 8 1}$ & $\mathbf{4 4}$ \\
& RNP & 570 & 30.1 & 424 & 27.4 \\
& RE & 103 & 5.4 & 64 & 4.1 \\
& RPP & $\mathbf{1 2 2 1}$ & $\mathbf{6 4 . 5}$ & $\mathbf{1 0 6 0}$ & $\mathbf{6 8 . 5}$ \\
\hline & & & &
\end{tabular}

La tabla 2 presenta los resultados del análisis inferencial. En categoría U-21, se obtuvo una asociación significativa entre la eficacia de recepción y el desplazamiento previo del receptor, tipo de recepción, posición del receptor, técnica de recepción y zona de recepción. Por el contrario, no se obtuvo asociación significativa entre la eficacia de recepción y la función del receptor. Por ello, esta variable no se incluyó en el modelo de regresión logística multinomial.

A pesar de que la posición del receptor mostró asociación significativa, no cumplió los criterios mínimos de la prueba de Chi-cuadrado por lo que no pudo ser introducida en el modelo final.

En categoría absoluta, el análisis inferencial mostro una asociación significativa entre la eficacia de recepción y el desplazamiento previo del receptor, posición del receptor y técnica de recepción. Por el contrario, no hubo asociación significativa entre la eficacia de recepción y la función del receptor, tipo de recepción y zona de recepción. Por ello, estas variables no pudieron ser incluidas en el modelo de regresión logística multinomial. 
Tabla 2. Asociación entre la eficacia de recepción y las variables del estudio

\begin{tabular}{ccccccc}
\hline Variables & \multicolumn{3}{c}{ U-21 } & \multicolumn{3}{c}{ Absoluto } \\
\cline { 2 - 7 } & $\mathbf{p .}$ & $\mathbf{2}$ & $\begin{array}{c}\text { V de } \\
\text { Cramer }\end{array}$ & $\boldsymbol{p .}$ & $\mathbf{2}$ & $\begin{array}{c}\text { V de } \\
\text { Cramer }\end{array}$ \\
\hline $\begin{array}{c}\text { Función del receptor } \\
\text { Desplazamiento previo del } \\
\text { receptor }\end{array}$ & .888 & 1.137 & .017 & .975 & .481 & .012 \\
$\begin{array}{c}\text { Tipo de recepción } \\
\text { Posición del receptor }\end{array}$ & $\mathbf{. 0 0 0}$ & 27.538 & .055 & $\mathbf{. 0 0 0}$ & 39.169 & .112 \\
Técnica de recepción & $\mathbf{. 0 0 0}$ & 59.746 & .086 & .099 & 10.687 & .059 \\
Zona de recepción & $\mathbf{. 0 0 0}$ & 77.941 & .143 & $\mathbf{. 0 2 6}$ & 11.096 & .060 \\
& $\mathbf{. 0 3 1}$ & 13.901 & .061 & .079 & 88.196 & .169 \\
& & & & &
\end{tabular}

En las Tablas 3 y 4 se muestran los modelos predictivos de las variables del estudio con la eficacia de la recepción, en los diferentes niveles.

En la categoría U-21 (Tabla 3), el desplazamiento previo del receptor, tipo de recepción, técnica de recepción y zona de recepción, fueron variables predictoras de la eficacia de recepción. Concretamente, en la comparación entre la recepción que permite primeros tiempos y la recepción que no permite primeros tiempos, desplazarse hacia delante o detrás, en lugar de no desplazarse, producía un incremento en la eficacia de recepción descendiendo las recepciones que no permiten primero tiempos, en lugar de las recepciones que permiten primeros tiempos.

Con relación al tipo de recepción, ante recepciones sin apoyos se incrementaban las recepciones que no permiten primeros tiempos, lo que provocaba un descenso en la eficacia de la recepción.

Finalmente, en relación con la técnica de recepción, recibir de dedos aumentaba la eficacia de la recepción, mientras que recibir de antebrazos lateral, tanto hacia la izquierda como a la derecha, descendía la eficacia de recepción. Dicho descenso de la eficacia era debido al incremento de las recepciones que no permiten primeros tiempos, en lugar de las recepciones que permiten primeros tiempos.

También en categoría U-21 (Tabla 3), pero en la comparación entre recepción que permite primeros tiempos y recepción error, se obtuvo, con relación al desplazamiento previo del receptor, que, si el jugador se desplazaba hacia delante o detrás o hacia el desplazamiento lateral, en lugar de no desplazarse, se incrementaba la eficacia de recepción, ya que descendían las recepciones error, en lugar de las recepciones que permiten primeros tiempos.

Referente al tipo de recepción, ante recepciones con un apoyo, de rodillas o sin apoyos, en lugar de recepciones con dos apoyos, en todos los casos, descendía la eficacia de recepción, por aumentarse las recepciones error, en lugar de las recepciones que permiten primeros tiempos.

Con relación a la técnica de recepción, recibir de dedos, en lugar de antebrazos de frente, aumentaba la eficacia de recepción, mientras que recibir de antebrazos 
lateral izquierdo, reducía la eficacia por incrementarse las recepciones error, en lugar de las recepciones que permiten primeros tiempos.

Finalmente, con relación a la zona de recepción, recibir en el pasillo de uno, en lugar del pasillo de seis, disminuía la eficacia de recepción, aumentándose las recepciones error, en lugar de las recepciones que permiten primeros tiempos.

\begin{tabular}{|c|c|c|c|c|c|c|c|c|c|}
\hline Variables & $\begin{array}{l}\text { RPP } \\
\%^{a}\end{array}$ & $\begin{array}{c}\text { RNP } \\
\%\end{array}$ & $\begin{array}{c}\text { OR } \\
\text { Bruto }\end{array}$ & $\begin{array}{c}\text { OR } \\
\text { Ajustado }\end{array}$ & $\mathbf{p}$ & $\begin{array}{c}\text { RE } \\
\%\end{array}$ & $\begin{array}{c}\text { OR } \\
\text { Bruto }\end{array}$ & $\begin{array}{c}\text { OR } \\
\text { Ajustado }\end{array}$ & p \\
\hline \multicolumn{10}{|c|}{ Desplazamiento previo del receptor } \\
\hline Antero-posterior & 66.8 & 29.1 & $\begin{array}{c}.862 \\
(.686-1.084)^{c}\end{array}$ & $\begin{array}{c}.784 \\
(.618-.995)^{c}\end{array}$ & .045 & 4.1 & $\begin{array}{c}.524 \\
(.323-.848)^{c}\end{array}$ & $\begin{array}{c}.387 \\
(.234-.640)^{c}\end{array}$ & .000 \\
\hline Lateral & 66.7 & 29.5 & $\begin{array}{c}.874 \\
(.676-1.131)\end{array}$ & $\begin{array}{c}.823 \\
(.631-1.073)\end{array}$ & .150 & 3.8 & $\begin{array}{c}.488 \\
(.276-.861)\end{array}$ & $\begin{array}{c}.422 \\
(.233-.764)\end{array}$ & .000 \\
\hline$\underset{\text { desplazamiento }}{\text { Sin }}$ & . & . & . & . & . & . & . & . & . \\
\hline \multicolumn{10}{|c|}{ Tipo de recepción } \\
\hline Un apoyo & 59.5 & 29.5 & $\begin{array}{c}1.159 \\
(.834-1.612)\end{array}$ & $\begin{array}{c}1.225 \\
(.871-1.724)\end{array}$ & .244 & 11 & $\begin{array}{c}3.333 \\
(1.945-5.710)\end{array}$ & $\begin{array}{c}4.715 \\
(2.613-8.507)\end{array}$ & .000 \\
\hline De rodillas & 60.6 & 31.8 & $\begin{array}{c}1.227 \\
(.882-1.707)\end{array}$ & $\begin{array}{c}1.173 \\
(.834-1.650)\end{array}$ & .258 & 7.6 & $\begin{array}{c}2.264 \\
(1.222-4.195)\end{array}$ & $\begin{array}{c}2.017 \\
(1.068-3.808)\end{array}$ & .031 \\
\hline Sin apoyos & 58.9 & 34.2 & $\begin{array}{c}1.358 \\
(1.034-1.784)\end{array}$ & $\begin{array}{c}1.346 \\
(1.015-1.785)\end{array}$ & .039 & 6.9 & $\begin{array}{c}2.125 \\
(1.233-3.663)\end{array}$ & $\begin{array}{c}2.563 \\
(1.445-4.547)\end{array}$ & .001 \\
\hline Dos apoyos ${ }^{b}$ & . & . & . & . & . & . & . & $\cdot$ & . \\
\hline \multicolumn{10}{|c|}{ Técnica de recepción } \\
\hline Dedos & 72.8 & 25.9 & $\begin{array}{c}.823 \\
(.650-1.042)\end{array}$ & $\begin{array}{c}.762 \\
(.593-.979)\end{array}$ & .034 & 1.3 & $\begin{array}{c}.175 \\
(.080-.386)\end{array}$ & $\begin{array}{c}.120 \\
(.053-.273)\end{array}$ & .000 \\
\hline Lateral izquierdo & 47.9 & 39.5 & $\begin{array}{c}1.905 \\
(1.336-2.715)\end{array}$ & $\begin{array}{c}1.846 \\
(1.289-2.645)\end{array}$ & .001 & 12.6 & $\begin{array}{c}2.657 \\
(1.542-4.578)\end{array}$ & $\begin{array}{c}2.272 \\
(1.273-4.056)\end{array}$ & .006 \\
\hline Lateral derecho & 48.2 & 45.7 & $\begin{array}{c}2.192 \\
(1.552-3.096)\end{array}$ & $\begin{array}{c}2.151 \\
(1.511-3.063)\end{array}$ & .000 & 6.1 & $\begin{array}{c}1.281 \\
(.633-2.595)\end{array}$ & $\begin{array}{c}1.268 \\
(.607-2.649)\end{array}$ & .528 \\
\hline De frente & . & . & . & . & . & . & . & . & . \\
\hline \multicolumn{10}{|c|}{ Zona de recepción } \\
\hline Pasillo 1 & 62.4 & 29.5 & $\begin{array}{c}1.032 \\
(.803-1.327)\end{array}$ & $\begin{array}{c}1.036 \\
(.803-1.337)\end{array}$ & .786 & 8.1 & $\begin{array}{c}1.746 \\
(1.088-2.802)\end{array}$ & $\begin{array}{c}1.842 \\
(1.125-3.015)\end{array}$ & .015 \\
\hline interferencia & 65.6 & 33.1 & $\begin{array}{c}1.105 \\
(.757-1.613)\end{array}$ & $\begin{array}{c}.977 \\
(.658-1.451)\end{array}$ & .909 & 1.3 & $\begin{array}{c}.272 \\
(.064-1.152)\end{array}$ & $\begin{array}{c}.272 \\
(.062-1.189)\end{array}$ & .084 \\
\hline Pasillo 5 & 65.2 & 30.2 & $\begin{array}{c}1.013 \\
(.788-1.303)\end{array}$ & $\begin{array}{c}1.062 \\
(.817-1.380)\end{array}$ & .654 & 4.6 & $\begin{array}{c}.953 \\
(.553-1.642)\end{array}$ & $\begin{array}{c}1.237 \\
(.695-2.203)\end{array}$ & .470 \\
\hline Pasillo $6^{\mathrm{b}}$ & . & . & . & . & . & . & . & . & . \\
\hline
\end{tabular}

En la categoría absoluta (Tabla 4), el desplazamiento previo del receptor y la técnica de recepción fueron las variables que mostraron predicción con la eficacia de recepción. Concretamente, en la comparativa entre la recepción que no permite primeros tiempos y la recepción que permite primeros tiempos, desplazarse antes de contactar con el balón, tanto hacia delante, hacia detrás o lateralmente, en lugar de no desplazarse, incrementaba la eficacia de recepción. Dicho incremento en la eficacia de recepción se produjo al disminuir las recepciones que no permiten primeros tiempos, en lugar de las recepciones que permiten primeros tiempos.

En relación con la técnica de recepción, recibir de dedos aumentaba la eficacia de la recepción, mientras que recibir de antebrazos lateral, tanto hacia la izquierda como a la derecha, descendía la eficacia de recepción, por 
incrementarse las recepciones que no permiten primeros tiempos, en lugar de las recepciones que permiten primeros tiempos.

En cuanto a la relación entre la recepción que permite primeros tiempos y la recepción error (Tabla 4), la técnica de recepción y la posición del receptor fueron variables predictoras de la eficacia de recepción. Concretamente, en la relación entre la recepción error y recepción que permite primeros tiempos, ante recepciones de antebrazos lateral izquierdo y derecho, en lugar de recepciones de antebrazos de frente, y recepciones en posición baja, en lugar de posición media, se incrementaban las recepciones error, en lugar de las recepciones que permiten primeros tiempos, disminuyendo esto la eficacia de recepción.

\begin{tabular}{|c|c|c|c|c|c|c|c|c|c|}
\hline Variables & $\begin{array}{l}\text { RPP } \\
\%^{a}\end{array}$ & $\begin{array}{c}\text { RNP } \\
\%\end{array}$ & $\begin{array}{c}\text { OR } \\
\text { Bruto }\end{array}$ & $\begin{array}{c}\text { OR } \\
\text { Ajustado }\end{array}$ & $p$ & $\begin{array}{c}\mathrm{RE} \\
\%\end{array}$ & $\begin{array}{c}\text { OR } \\
\text { Bruto }\end{array}$ & $\begin{array}{c}\text { OR } \\
\text { Ajustado }\end{array}$ & $\mathrm{p}$ \\
\hline \multicolumn{10}{|c|}{ Desplazamiento previo del receptor } \\
\hline Antero-posterior & 75.1 & 22 & $\begin{array}{c}.521 \\
(.397-.648)\end{array}$ & $\begin{array}{c}.582 \\
(.439-.770)^{c}\end{array}$ & .000 & 2.9 & $\begin{array}{c}.442 \\
(.232-.844)\end{array}$ & $\begin{array}{c}.520 \\
(.268-1.008)^{c}\end{array}$ & .053 \\
\hline Lateral & 75.7 & 20.7 & $\begin{array}{c}.486 \\
(.361-.655)\end{array}$ & $\begin{array}{c}.502 \\
(.369-.685)\end{array}$ & .000 & 3.5 & $\begin{array}{c}.543 \\
(.284-1.037)\end{array}$ & $\begin{array}{c}.605 \\
(.310-1.181)\end{array}$ & .141 \\
\hline $\begin{array}{c}\text { Sin } \\
\text { desplazamiento }^{\mathrm{b}}\end{array}$ & . & . & $\cdot$ & $\cdot$ & $\cdot$ & $\cdot$ & $\cdot$ & $\cdot$ & . \\
\hline \multicolumn{10}{|c|}{ Posición del receptor } \\
\hline Alta & 42.1 & 42.7 & $\begin{array}{c}1.070 \\
(.845-1.354)\end{array}$ & $\begin{array}{c}1.159 \\
(.875-1.533)\end{array}$ & .304 & 42.2 & $\begin{array}{c}1.264 \\
(.727-2.198)\end{array}$ & $\begin{array}{c}1.232 \\
(.664-2.286)\end{array}$ & .508 \\
\hline Baja & 6.7 & 8.7 & $\begin{array}{c}1.374 \\
(.895-2.109)\end{array}$ & $\begin{array}{c}1.386 \\
(.893-2.152)\end{array}$ & .146 & 17.2 & $\begin{array}{c}3.236 \\
(1.533-6.830)\end{array}$ & $\begin{array}{c}3.389 \\
(1.579-7.273)\end{array}$ & .002 \\
\hline Media $^{\mathrm{b}}$ & . & . & $\cdot$ & $\cdot$ & . & . & $\cdot$ & $\cdot$ & . \\
\hline \multicolumn{10}{|c|}{ Técnica de recepción } \\
\hline Dedos & 85.7 & 13.2 & $\begin{array}{c}.469 \\
(.297-.740)\end{array}$ & $\begin{array}{c}.471 \\
(.284-.780)\end{array}$ & .003 & 1.1 & $\begin{array}{c}.301 \\
(.071-1.278)\end{array}$ & $\begin{array}{c}.329 \\
(.072-1.502)\end{array}$ & .151 \\
\hline $\begin{array}{l}\text { Antebrazos } \\
\text { izquierdo }\end{array}$ & 51.6 & 40.4 & $\begin{array}{c}2.385 \\
(1.763-3.227)\end{array}$ & $\begin{array}{c}2.269 \\
(1.637-3.146)\end{array}$ & .000 & 8 & $\begin{array}{c}3.643 \\
(1.991-6.666)\end{array}$ & $\begin{array}{c}3.577 \\
(1.855-6.899)\end{array}$ & .000 \\
\hline $\begin{array}{l}\text { Antebrazos } \\
\text { derecho }\end{array}$ & 54.7 & 38.8 & $\begin{array}{c}2.161 \\
(1.568-2.978)\end{array}$ & $\begin{array}{c}1.998 \\
(1.422-2.807)\end{array}$ & .000 & 6.5 & $\begin{array}{c}2.812 \\
(1.437-5.501)\end{array}$ & $\begin{array}{c}2.715 \\
(1.331-5.535)\end{array}$ & .000 \\
\hline $\begin{array}{l}\text { Antebrazos de } \\
\text { frente }^{b}\end{array}$ & . & . & $\cdot$ & $\cdot$ & . & $\cdot$ & $\cdot$ & . & . \\
\hline
\end{tabular}

\section{DISCUSIÓN}

En la actualidad encontramos estudios que muestran que la recepción, a pesar de ser una acción intermedia tiene un papel fundamental en la construcción del ataque (Palao et al., 2006; Silva, Lacerda, \& João, 2013), afectando de forma determinante a la calidad del mismo (Eom \& Schutz, 1992). Con el objetivo de obtener información para mejorar el proceso de entrenamiento de la recepción, la presente investigación pretendió conocer qué variables de la recepción predecían la eficacia de dicha acción, en diferentes niveles de juego (U-21 y absoluto), en voleibol masculino.

El análisis descriptivo mostró resultados similares tanto en categoría U-21 como en absoluta, en todas las variables (función del receptor, desplazamiento previo del receptor, tipo de recepción, técnica de recepción, zona de recepción), excepto en la posición del receptor. Concretamente, en dichas categorías fue lo 
más frecuente la recepción realizada por el jugador "otro", lo más frecuente fue realizar la recepción sin desplazamiento previo, la técnica de recepción más frecuente fue con dos apoyos, el tipo de recepción más frecuente fue la recepción de antebrazos de frente, la zona de recepción más frecuente fue la zona seis y, la eficacia más frecuente fue la que permitía primeros tiempos. En cuando a la posición del receptor, en U-21 la más frecuente fue la posición alta. Finalmente, en la categoría absoluta, la posición del receptor más frecuente fue la posición baja.

En línea con nuestros resultados, Ureña et al. (2002), en alto nivel, obtuvieron, en categoría absoluta, que lo más frecuente fue que el receptor no se desplazara para recibir $(72,9 \%)$, y que la técnica de recepción más empleada fuera la recepción de antebrazos (89\%). Por su parte, Rentero et al. (2015), en alto nivel, obtuvieron como zona de recepción más frecuente la zona seis $(51,4 \%)$. Unido a ello, Finalmente, Costa et al. (2017), en alto nivel, obtuvieron que lo más frecuente fue la recepción excelente. Por otro lado, a diferencia de los resultados del estudio, Carrero et al. (2017), en categoría juvenil, obtuvieron que en la mayoría de las ocasiones, los receptors recibieron con ningún o un único apoyo $(52,7 \%)$, no ocurriendo lo mismo en el presente estudio.

En cuanto al análisis predictivo, los resultados mostraron que el desplazamiento previo del receptor y la técnica de recepción fueron predictoras en U-21 y absoluta; el tipo y zona de recepción predijeron únicamente en U-21; la posición del receptor predijo únicamente en el nivel absoluto.

Tanto en U-21 como en nivel absoluto, el desplazamiento previo del receptor fue predictor de la eficacia de recepción. Concretamente, ante desplazamientos anteroposteriores y laterales se incrementaba la eficacia de recepción. A diferencia de nuestros resultados, Paulo et al. (2016), en un estudio en voleibol masculino de alto nivel, obtuvieron que, cuando el receptor se desplazaba para realizar la recepción, se incrementaban las posibilidades de que la recepción no fuese perfecta. Estos resultados podrían estar condicionados por las propias características de la prueba empleada en el estudio (una tarea creada específicamente para el mismo), así como por el reducido número de sujetos (8).

Barsingerhorn et al. (2013) indicaron la complejidad que tiene la tarea de desplazarse tras el saque, para llegar a una posición concreta para enviar el balón al colocador. Dichos autores indicaban que, llegar a un lugar determinado, en un momento concreto, dependía de factores como la velocidad del movimiento del jugador, el tiempo disponible y la trayectoria del vuelo del balón con relación al jugador.

A pesar de la dificultad que conlleva desplazarse tras el saque para recibir, nuestros resultados mostraron, en los dos niveles de juego, que cuando los receptores se desplazaban para recibir, eran más eficaces que cuando no lo hacían. Este aspecto puede ser debido a que, los sacadores buscan zonas concretas del campo, como pueden ser líneas de fondo (Moreno, García de Alcaraz, Moreno, Molina, \& Santos, 2007), zonas de interferencias (LopezMartinez \& Palao, 2009), con el objetivo de dificultar el mismo. Esto provoca que los jugadores estén muy acostumbrados a tener que desplazarse para realizar 
la recepción, no afectando el desplazamiento a la eficacia de la acción, sino siendo el desplazamiento necesario. Además de ello, los jugadores participantes en nuestra investigación pueden considerarse de un nivel superior al resto, ya que son integrantes de una selección nacional.

Referente a la técnica de recepción, esta variable fue predictora de la eficacia de la recepción, tanto en la categoría U-21 como en la absoluta. Las recepciones de dedos incrementaban la eficacia de recepción, mientras que, las recepciones de antebrazos laterales, realizadas por la izquierda o por la derecha, en lugar de frente, producían un descenso de la misma. En la bibliografía no hemos encontrado ningún estudio en el que se relacione la técnica de recepción con la eficacia de la misma. Sin embargo, Afonso et al. (2012) obtuvieron que la técnica de recepción (recepción de antebrazos) incrementaba las recepciones que no permitían primeros tiempos, no llegando los balones a una zona ideal de colocación.

En ocasiones, cuando el balón de saque es dirigido al fondo del campo y al pecho del jugador, es muy difícil que el receptor pueda realizar una recepción de antebrazos de frente utilizando, en dichas ocasiones, una técnica de emergencia o técnicas avanzadas (Shondell, 2002). A pesar de que el uso de estas técnicas es usual, la utilización de las mismas está asociada a condiciones de juego no ideales, por lo que, aun ejecutando la técnica correcta, afecta a la recepción, disminuyendo su eficacia.

Centrándonos en los resultados de los jugadores U-21, el tipo de recepción y la zona de recepción, fueron variables predictoras únicamente en dicho nivel. Concretamente, haciendo referencia al tipo de recepción, recibir con un apoyo, de rodillas o sin apoyos, en lugar de con dos apoyos, descendía la eficacia de la recepción. Carrero et al. (2017), en un estudio realizado en categoría U-19, obtuvieron resultados similares a los de la presente investigación, ya que, cuando recibían con un apoyo o ningún apoyo, se incrementaban las recepciones malas. Según Dearing (2003), los pies son el éxito del pase de recepción, pudiendo producir un descenso de la eficacia de recepción en aquellas recepciones que no se realizan con dos apoyos.

Como indicamos anteriormente, la zona recepción fue la otra variable predictora en U-21, y no en nivel absoluto. Los resultados mostraron que recibir en el pasillo de uno, en lugar del pasillo de seis, disminuía la eficacia de la recepción. En línea con nuestros resultados, a pesar de no tener la misma distribución en cuanto a las zonas, Joao y Pires (2015), obtuvieron que, cuando la recepción se realizaba en las zonas centrales del campo, se incrementaba la eficacia de recepción.

Pese a que el mayor número de saques suele dirigirse hacia la zona central del campo (Rentero et al., 2015), es allí donde se sitúan los jugadores principales en recepción, el libero (Joao \& Pires, 2015) o el receptor zaguero. Unido a ello, los saques que se realizan a zonas centrales suelen ser saques con el objetivo de no arriesgar y asegurar el mismo (Gil-Arias et al., 2016), no creando una gran dificultad en la recepción. Esto produce que, recibir en zonas centrales del campo, favorezca el incremento de la eficacia en la acción de recepción. 
Referente al nivel absoluto, la posición del receptor fue la única variable que resultó predictora, únicamente, en dicho nivel. Concretamente, cuando el receptor recibía en una posición baja, la eficacia de recepción descendía, puesto que se incrementaba la frecuencia de recepción error, en lugar de una recepción que permitiera los primeros tiempos.

La altura óptima de contacto de la pelota con los brazos es entre las rodillas y la cintura (Miller, 2005, 55), altura que no se tiene cuando el jugador recibe con una posición baja, al tener los brazos por debajo de las rodillas estando los mismos muy cerca del suelo. Todo esto produce que, ante recepciones con posiciones bajas, la eficacia de la recepción descienda.

\section{CONCLUSIONES}

Tanto en categoría U-21, como en categoría absoluta, lo más frecuente fue que recibiese el jugador "otro" (jugador con funciones diferentes a las del atacante delantero y libero), que no hubiese desplazamiento antes de la recepción, que se recibiese con dos apoyos, que se recibiese a través de una técnica de antebrazos de frente y que la eficacia de recepción más frecuente fuese la recepción que permite primeros tiempos. En cambio, en la categoría U-21 la posición del receptor más frecuente fue la alta, siendo, en categoría absoluta, la posición baja. En ambos niveles, el desplazamiento previo del receptor y la técnica de recepción fueron variables predictoras. Sólo en U-21 fueron predictoras las variables tipo de recepción y zona de recepción. Sólo en nivel absoluto, la posición del receptor fue predictora de la eficacia de recepción.

Estos resultados aportan información sobre las características de la recepción que influyen en su eficacia, en cada nivel de juego. Estos datos pueden orientar el proceso de entrenamiento de la recepción en diferentes niveles de juego, contribuyendo a optimizar el mismo.

NOTA: El presente artículo se encuadra en una serie de artículos pertenecientes a la Tesis Doctoral titulada "Análisis de las variables que afectan a la recepción y la colocación en voleibol", realizada por Dña. Jara González Silva, en la Universidad de Extremadura.

\section{REFERENCIAS BIBLIOGRÁFICAS}

Afonso, J., Esteves, F., Araújo, R., Thomas, L., \& Mesquita, I. (2012). Tactical determinants of setting zone in elite men's volleyball. Journal of Sports Science and Medicine, 11, 64-70.

Barsingerhorn, A., Zaal, F., De Poel, H., \& Pepping, G.-J. (2013). Shaping decision in volleyball. An ecological approach to decision-making in volleyball passing. International Journal of Sport Psychology, 44, 197-214. https://doi.org/10.7352/lJSP

Benerink, N. H., Bootsma, R. J., \& Zaal, F. T. J. M. (2015). Different temporal bases for body and arm movements in volleyball serve reception. Scandinavian Journal of Medicine and Science in Sports, 25, 603-609. https://doi.org/10.1111/sms.12384 
Carrero, I., Fernández-Echeverría, C., González-Silva, J., Conejero, M., \& Moreno, M. P. (2017). Estudio predictivo de la eficacia de la recepción en voleibol juvenil masculino. Retos, 32, 214-218. https://doi.org/10.47197/retos.v0i32.56060

Costa, G., Castro, H., Freire, A., Evangelista, B., Pedrosa, G., Ugrinowitsch, H., \& Praça, G. (2018). High level of Brazilian men 's volleyball: characterization and difference of predictive factors of back row attack. Motricidade, 14(1), 58-65. https://doi.org/10.6063/motricidade.12221

Costa, G., Maia, M., Rocha, A., Martins, L., Gemente, F., Campos, M., ... Freire, A. (2017). Association between effect of reception and game procedures in high-level Brazilian volleyball: The case of the women's "Superliga" champion team. Revista Brasileira de Cineantropometria e Desempenho Humano, 19(6), 663-675. https://doi.org/10.5007/1980$0037.2017 v 19 n 6 p 663$

Data Volley. (2010). Data Volley System Valuation.

Dearin, J. (2003). Receiving serve. In Volleyball fundamentals (pp. 21-30). Human Kinetics: Champaign

Eom, H. J., \& Schutz, R. W. (1992). Statistical analyses of volleyball team performance. Research Quarterly for Exercise and Sport, 63(1), 11-18. https://doi.org/10.1080/02701367.1992.10607551

Fernández-Echeverria, C., Mesquita, I., González-Silva, J., Claver, F., \& Moreno, M. P. (2017). Match analysis within the coaching process: A critical tool to improve coach efficacy. International Journal of Performance Analysis in Sport, 17(1-2), 149-163. https://doi.org/10.1080/24748668.2017.1304073

Fleiss, J., Levin, B., \& Paik, M. (2003). Statistical methods for rates and proportions. New York: John Wiley \& Sons. https://doi.org/10.1002/0471445428

García-Alcaraz, A., Palao, J. M., \& Ortega, E. (2014). Perfil rendimiento técnicotáctico de la recepción en función de la categoría de competición en voleibol masculino. Kronos.Rendimiento en el deporte, 13(1). https://revistakronos.info/articulo/perfil-de-rendimiento-tecnico-tactico-de-larecepcion-en-funcion-de-la-categoria-de-competicion-en-voleibolmasculino-1706-sa-x57cfb272429db/

Gil-Arias, A., Claver, F., Fernández-Echeverría, C., Moreno, A., \& Moreno, M. P. (2016). Análisis comparativo del saque en voleibol entre los campeonato de España 2005/2010. Revista Internacional de Medicina y Ciencias de la Actividad Física y el Deporte, 16(62), 439-456.

Hair, J., Black, W., Babin, B., \& Anderson, R. (2014). Multivariate Data Analysis (7. ${ }^{a}$ ed.). Harlow: Pearson.

Hughes, M., Caudrelier, T., James, N., Redwood-Brown, A., Donnelly, I., Kirkbride, A., \& Duschesne, C. (2012). Moneyball and soccer - An analysis of the key performance indicators of elite male soccer players by position. Journal of Human Sport and Exercise, 7(2), 402-412. https://doi.org/10.4100/jhse.2012.72.06

Joao, P. V., \& Pires, P. M. (2015). Eficácia do Side-out no Voleibol sénior masculino em função do jogador interveniente. Motricidade, 11(4), 142-150. https://doi.org/10.6063/motricidade.6302

Lopez-Martinez, A. B., \& Palao, J. M. (2009). Effect of Serve Execution on Serve 
Efficacy in Men's and Women's Beach Volleyball. International Journal of Applied Sports Sciences, 21(1), 1-16.

Marelić, N., Resetar, T., \& Jankovic, V. (2004). Discriminant analysis of the sets won and the sets lost by one team in a1 italian volleyball league a case study. Kinesiology, 36(1), 75-82.

Miller, B. (2005). The volleyball handbook. Winning essentials for players and coaches. Champaign, IL: Human Kinetics.

Moreno, M. P., García de Alcaraz, A., Moreno, A., Molina, J. J., \& Santos, J. (2007). Estudio de la dirección del saque en la superliga masculina de voleibol. Motricidad. European Journal of Human Movement, 18, 111-134.

O'Donoghue, P., \& Holmes, L. (2015). Data Analysis in Sport. London: Routledge. https://doi.org/10.4324/9781315816357

O`Donoghue, P. (2010). Research methods for sports performance analysis. London: Routledge.

Palao, J. M., Santos, J., \& Urena, A. (2006). Effect of reception and dig efficacy on spile performance and manner of execution in volleyball. Journal of human Movement Studies, 51(4), 221-238. https://doi.org/10.1017/CBO9781107415324.004

Parsiaouras, A., Moustakidis, A., Charitonidis, K., \& Kokaridas, D. (2010). Volleyball technical skills as winning and qualification factors during the Olympic Games 2008. International Journal of Performance Analysis in Sport, 10, 115-120. https://doi.org/10.1080/24748668.2010.11868507

Paulo, A., Zaal, F., Fonseca, S., \& Araújo, D. (2016). Predicting Volleyball ServeReception. Frontiers in psychology, 7(1), 1694-2016. https://doi.org/10.3389/fpsyg.2016.01694

Peña, J., Rodríguez-Guerra, J., Buscà, B., \& Serra, N. (2013). Which skills and factors better predict winning and losing in high-level men's volleyball? Journal of Strength and Conditioning Research, 27(9), 2487-2493. https://doi.org/10.1519/JSC.0b013e31827f4dbe

Rentero, L., João, P. V., \& Moreno, M. P. (2015). Análisis de la influencia del libero en diferentes fases del juego en voleibol. Revista Internacional de Medicina y Ciencias de la Actividad Fisica y del Deporte, 15(60), 739-756. https://doi.org/10.15366/rimcafd2015.60.008

Sánchez, M., González-Silva, J., Fernández-Echeverría, C., Claver, F., \& Moreno, M. P. (2019). Participación e influencia del libero en recepción y defensa, en voleibol juvenil. Revista Internacional de Medicina y Ciencias de la Actividad Fisica y del Deporte, 19(73), 45-62. https://doi.org/10.15366/rimcafd2019.73.004

Sellinger, A., \& Ackermann-Blount, J. (1985). El Voleibol de Potencia. Buenos Aires: Confederación Argentina de Voleibol.

Silva, M., Lacerda, D., \& João, P. V. (2013). Match analysis of discrimination skills according to the setter attack zone position in high level volleyball. International Journal of Performance Analysis in Sport, 13, 452-460. https://doi.org/10.1080/24748668.2013.11868661

Shondell, S. (2002). Receiving Serves. En D. Shondell \& C. Reynaud (Eds.), The Volleyball Coaching Bible (pp. 177-186). Champaign, IL: Human Kinetics.

Stamm, R., Stamm, M., \& Thomson, K. (2005). Role of adolescent female volleyball players'psychophysiological properties and body build in performance of different elements of the game. Perceptual and Motor Skills, 
101, 108-120. https://doi.org/10.2466/PMS.101.5.108-120

Ureña, A., Calvo, R., \& Lozano, C. (2002). Estudio de la recepción del saque en el voleibol masculino español de elite tras la incorporación del jugador libero. Revista internacional de ciencias de la actividad fisica y del deporte, 2(4), 37-49.

Wright, C., Atkins, S., \& Jones, B. (2012). An analysis of elite coaches' engagement with performance analysis services (match, notational analysis and technique analysis). International Journal of Performance Analysis in Sport, 12(2), 436-451. https://doi.org/10.1080/24748668.2012.11868609

Referencias totales / Total references: 34 (100\%)

Referencias propias de la revista / Journal's own references: 4 (11,7\%)

Rev.int.med.cienc.act.fís.deporte - vol. 21 - número 83 - ISSN: 1577-0354 